\title{
Identification and Assessment of Public Health Surveillance Gaps under the IHR (2005)
}

\author{
Ngozi Erondu*1, Betiel Hadgu Haile ${ }^{1}$, Lisa Ferland ${ }^{1}$, Meeyoung Park ${ }^{1}$, Affan Shaikh ${ }^{1}$, \\ Heather Meeks ${ }^{2}$ and Scott JN McNabb ${ }^{1}$
}

${ }^{1}$ Public Health Practice, Atlanta, GA, USA; ${ }^{2}$ Defense Threat Reduction Agency, Washington, DC, USA

\section{Objective}

To conceive and develop a model to identify gaps in public health surveillance performance and provide a toolset to assess interventions, cost, and return on investment (ROI).

\section{Introduction}

Under the revised International Health Regulations (IHR [2005]) one of the eight core capacities is public health surveillance. In May 2012, despite a concerted effort by the global community, the World Health Organization (WHO) reported out that a significant number of member states would not achieve targeted capacity in the IHR (2005) surveillance core capacity.

Currently, there is no model to identify and measure these gaps in surveillance performance. Likewise, there is no toolset to assess interventions by cost and estimate the ROI.

We developed a new conceptual framework that: (1) described the work practices to achieve effective and efficient public health surveillance; (2) could identify impediments or gaps in performance; and (3) will assist program managers in decision making.

\section{Methods}

Published articles and grey-literature reports, manuals and logic model examples were gathered through a literature review of PubMed, Web of Science, Google Scholar, and other databases. Logic models were conceived by categorizing discrete surveillance inputs, activities, outputs, and outcomes. Indicators were selected from authoritative sources or developed and then mapped to the logic model elements. These indicators will be weighted using the principle component analysis (PCA), a method for enhanced precision of statistical analysis. Finally, on the front end of the tool, indicators will graphically measure the surveillance gap expressed through the tool's architecture and provide information using an integrated cost-impact analysis.

\section{Results}

We developed five public health surveillance logic models: for IHR (2005) compliance; event-based; indicator-based; syndromic; and predictive surveillance domains. The IHR (2005) domain focused on national-level functionality, and the others described the complexities of their specific surveillance work practices. Indicators were then mapped and linked to all logic model elements.

\section{Conclusions}

This new framework, intended for self-administration at the national and subnational levels, measured public health surveillance gaps in performance and provided cost and ROI information by intervention. The logic model framework and PCA methodology are tools that both describe work processes and define appropriate variables used for evaluation. However, both require real-world data. We recommend pilot testing and validation of this new framework. Once piloted, the framework could be adapted for the other IHR (2005) core capacities.

\section{Keywords}

Public health surveillance; Evaluation; IHR (2005); Gaps assessment; Cost-impact analysis

\section{Acknowledgments}

Defense Threat Reduction Agency and the World Health Organization

\section{References}

1. Implementation of the International Health Regulations., Stat. Resolution WHA65.23 ( 26 May 2012 ).

2. May L, Chretien JP, Pavlin JA. Beyond traditional surveillance: applying syndromic surveillance to developing settings - opportunities and challenges. BMC Public Health. 2009;9:242. Epub 2009/07/18.

3. Wilson K, McDougall C, Fidler DP, Lazar H. Strategies for implementing the new International Health Regulations in federal countries. Bulletin of the World Health Organization. 2008;86(3):215-20. Epub 2008/03/28.

4. Organization WH. International Health Regulations (2005) Second Edition. 2008.

5. Sturtevant JL, Anema A, Brownstein JS. The new International Health Regulations: considerations for global public health surveillance. Disaster Med Public Health Prep. 2007;1(2):117-21. Epub 2008/04/05.

6. Lyons S, Zidouh A, Ali Bejaoui M, Ben Abdallah M, Amine S, Garbouj $\mathrm{M}$, et al. Implications of the International Health Regulations (2005) for communicable disease surveillance systems: Tunisia's experience. Public Health. 2007;121(9):690-5. Epub 2007/06/05.

7. Calain P. Exploring the international arena of global public health surveillance. Health Policy Plan. 2007;22(1):2-12. Epub 2007/01/24.

8. Baker MG, Forsyth AM. The new International Health Regulations: a revolutionary change in global health security. $\mathrm{N} \mathrm{Z} \mathrm{Med} \mathrm{J.}$ 2007;120(1267):U2872. Epub 2007/12/25.

9. Cash RA, Narasimhan V. Impediments to global surveillance of infectious diseases: consequences of open reporting in a global economy. Bulletin of the World Health Organization. 2000;78(11): 1358-67. Epub 2001/01/06

10. Fidler DP. Globalization, international law, and emerging infectious diseases. Emerg Infect Dis. 1996;2(2):77-84. Epub 1996/04/01.

11. Organization WH. World Health Organization: Disease Surveillance. Weekly Epidemiological Record [Internet].1998.

*Ngozi Erondu

E-mail: ngozierondu@gmail.com 